\title{
Determinants of co-movement and of lead and lag behavior of business cycles in the Eurozone
}

\author{
Hasan Engin Duran ${ }^{\mathrm{a}}$ and Alexandra Ferreira-Lopes ${ }^{\mathrm{b}}$

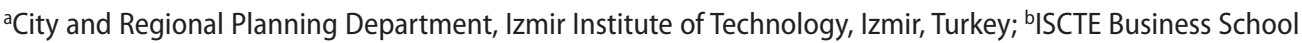 \\ Economics Department, and BRU-IUL, Instituto Universitário de Lisboa (ISCTE - IUL), Lisbon, Portugal
}

\begin{abstract}
In this paper we study business cycle correlations in the Eurozone and its determinants. Additionally, we also analyze the determinants of the lead and lag behavior of business cycles in the Eurozone. We explore the relevance, in the Eurozone context, using GDP and employment as the business cycle measures, of the determinants of business cycle synchronization identified in the literature, namely bilateral trade intensity, dissimilarity of labor market rigidity, dissimilarity in industrial structures, financial openness, and foreign direct investment relations. We estimate a simultaneous 4-equations model by Ordinary Least Squares (OLS) and three-stage least square to investigate empirically the above-mentioned determinants of business cycle correlation. Bilateral trade relations present a positive influence on business cycle correlations, while the dissimilarity of labor market rigidity presents a negative influence. The rest of the above-mentioned variables are non-significant. These results are robust to the use of the HodrickPrescott-filter and first differences as the de-trending methods, as well as the use of GDP as the business cycle measure, excluding the financial crisis years (2008 and 2009). Results for employment as the business cycle measure are in contrast with the previous ones, and found industrial dissimilarity to be the relevant variable to determine business cycles synchronization. In what concerns the determinants of the lead and lag behavior, results show that the member states of the Eurozone that usually lead the cycle are the ones that are wealthier, with strict employment legislation, more specialized in construction and finance sectors, and more prone to international capital movements. Differences in the determinants between contemporaneous business cycles and lead and lag behavior of business cycles are especially important for policy-makers in the Eurozone to know about, in particular if asymmetric shocks between countries are set in place.
\end{abstract}

\section{ARTICLE HISTORY}

Received 4 February 2016 Accepted 14 October 2016

\section{KEYWORDS}

Bilateral business cycles correlations; lead and lag behavior of business cycles; labor market flexibility; external migration

\section{JEL CODES}

C3; E32; F15; F21; F22; F44

\section{Introduction}

Since 1957 that the European Union (EU) has been both increasing in the number of member countries, and also increasing in the degree of economic integration. The level of the European integration process has settled, so far, in 19 (out of 28) member states sharing 
a common currency (the euro), ruled by an European Central Bank (ECB), the so-called European and Monetary Union (EMU), and 28 member states with independent fiscal policies, sharing a common market. Additionally, at the exception of the UK and Denmark, all EU member countries will have to eventually join the EMU sometime in the future. ${ }^{1}$ The EMU, also designated by Eurozone, implies the loss of monetary policy independence, i.e. the loss of interest rates and exchange rates as monetary policy instruments. This loss implies, for the Eurozone monetary policy to be successful in all Eurozone member countries, that countries share a high degree of business cycles synchronization.

Business cycle synchronization is an important factor for Eurozone policy-makers to take into consideration when making decisions about their policies, since lack of synchronization of business cycles, i.e. a lead or a lag behavior of business cycles, may incite heterogeneous effects of these policies. Likewise, a sound understanding on the determinants of business cycle synchronization in the Eurozone is of extreme importance to create tailor-made policies for member countries when facing asymmetric shocks. In this work we tackle the determinants of Eurozone business cycle synchronization, taking into consideration most of the determinants of business cycle synchronization identified in the business cycle literature. Additionally, we added two labor market variables, which we think are important in the context of the European integration process and the possibility of asymmetric shocks - (bilateral) dissimilarity of labor market rigidities, using data for the strictness of employment protection from the Organization for Economic Cooperation and Development (OECD), and - dissimilarity of external labor mobility, using net external migration from the EUROSTAT. We think that these variables are important to analyze as determinants of business cycles synchronization, since Eurozone member countries having loss monetary policy and having to obey restrict fiscal policies, can use the labor market as a cushion for asymmetric shocks. These two variables have never been used in the literature about the determinants of business cycle synchronization.

The literature about the determinants of business cycle synchronization is a fertile field of research. Past works have concluded that the most important determinants of business cycle synchronization are trade relations, characteristics of the labor market, labor migration, differences in sectoral specialization, financial openness, and foreign direct investment (FDI) relations. Our work will focus on the Eurozone. ${ }^{2}$

A set of papers has studied the above-mentioned determinants jointly for the EU and/ or EMU. Böwer and Guillemineau (2006) is the first paper that we have knowledge of that has studied the determinants of business cycle synchronization in the Eurozone. The authors apply the extreme bound analysis to the study of traditional (bilateral trade, trade and sector specialization, labor protection, exchange rates variations, etc.) and also to new determinants, such as policy and structural indicators for a period of 25 years (1980-2004). The theory of endogeneity of optimum currency area (OCA) seems to be a reasonable explanation to explain the business cycle synchronization, with trade playing an important role, in particular intra-industry trade. Fiscal policy and the financial and industrial sectors were important during the Single Market phase, while short-term interest rate differentials are relevant since the start of the EMU. Furceri and Karras (2008) analyze if business cycles in the EU have become more synchronized after the Euro was introduced and which variables can account for this. Hence, the direct focus, of the paper is not the Eurozone, although the paper studies nine Eurozone countries (Austria, Belgium, Finland, France, Germany, Greece, Italy, Netherlands, and Spain) and compares it with Denmark, Sweden, and the UK. 
Using quarterly data from 1993 until 2004, they uncovered that trade-related factors, such as exports and imports, were the main determinants of the increase in business cycle synchronization after the introduction of the euro in 1999, and not so much fiscal policy variables. The survey by de Haan, Inklaar, and Jong-A-Pin (2008) about business cycle convergence in the Eurozone and its determinants has found clear-cut conclusions about the positive role of trade intensity in increasing business cycle synchronization, while empirical evidence for other factors (financial openness, sectoral specialization, employment protection, fiscal policy variables, monetary policy variables, FDI, among others) is mixed. Siedschlag and Tondl (2011) using regional data for 208 regions for the period 1989-2002 analyze the role of regional trade integration, industry specialization and exchange rate volatility on regional output growth synchronization using a system of simultaneous equations. While trade integration promotes synchronization, industry specialization and exchange rate volatility are factors of divergence of business cycles. An example of this type of study, but for the EU, is Antonakakis and Tondl (2014). Anagnostou, Panteladis, and Tsiapa (2015) study business cycle synchronization in 14 EU countries' regions, between 1980 and 2009. The authors, among other things, study the driving factors of business cycles synchronization, using a panel three-stage least squares (SLSs), such as trade integration, sectoral patterns of specialization, and regional productivity related to a gravity index, which they found to be significant in explaining business cycles synchronization. Asteriou and Moudatsou (2015) analyze the determinants of business cycle synchronization in the EU between 1998 and 2011, which takes into account the sovereign debt crisis period. The authors analyze bilateral FDI and bilateral trade in goods, and their relationship with business cycles co-movements, and found that while trade is important for business cycles synchronization (only before the crisis), FDI presents no direct effect. Contrary to these findings, results of the work by Caporale, De Santis, and Girardi (2015), distinguishing between 11 core and periphery countries of the EMU in the period from 1988 to 2011, find evidence that the specialization paradigm prevails, instead of the endogeneity of the OCAs explanation. Pentecôte, Poutineau, and Rondeau (2015) study business cycle synchronization in the oldest 11 members of the Eurozone for the period between 1995 and 2007, using existing (intensive margin) and new trade (extensive margin) flows, as well as other variables, such as sectoral specialization, common border, common language, and some macroeconomic variables. The authors uncover that existing trade flows have a positive effect on business cycles synchronization, while new trade flows have a negative (indirect) effect, as well as specialization. Arestis and Phelps (2016) analyze the determinants of business cycle synchronization, and its possible endogeneity, in a panel for the period between 1994 and 2013, for the Eurozone, for the Central and Eastern European Countries (CEECs), Northern European countries, and Candidate countries for euro adoption. The authors find that trade and spillover channels related to monetary integration are important variables to assess.

Some other papers have studied only one set of determinants. Fidrmuc and Korhonen (2006) perform a meta-analysis on the business cycles correlations between the Eurozone and the eight CEECs. The authors don't study the determinants of business cycles correlations, but they study the degree of synchronization. They conclude that several CEECs have already achieved a significant degree of business cycles synchronization with the Eurozone. They also find evidence that results (correlations) are sensitive to different methodologies for calculating business cycles. Hauge and Skulevold (2011) analyze the role of fiscal policy on business cycle synchronization in the Eurozone. The authors found, using panel data 
techniques, that convergence of automatic stabilizers (government revenues and expenditures) increases business cycle synchronization for the period between 1980 and 2010, as well as convergence of accumulated government debt. Kappler (2011) studies the relationship between bilateral trade intensity and business cycle synchronization in an augmented vector auto-regressive model with an unobserved common factor structure, for the Eurozone. The author finds that in the short run, trade does not explain business cycles synchronization, although countries with stronger trade ties tend to have more synchronized business cycles in the long run. Gouveia and Correia (2013) analyze synchronization between 1981 and 2011 for Southern European countries (Greece, Italy, Portugal, and Spain) vis-à-vis the other 8 Eurozone member countries in the sample, using intra-EMU trade as the main explanation for business cycle synchronization, founding a positive relation between trade intensity and cyclical correlations in the Southern countries. Solomos, Papageorgiou, and Koumparoulis (2013) examines several financial sectors indicators as possible determinants of business cycles between 1996 and 2011 for the Eurozone, using EGLS, GLM, and fixed-effects methods. Variables such as the total value of stocks traded, private sector debt, and net inflows of FDI are meaningful determinants of business cycle, while results for financial depth are mixed.

We extend Böwer and Guillemineau (2006) analysis, adding variables such as external migration and FDI and also to a new analysis of leads and lags and its determinants, which will help in the understanding of how to deal with the possibility of asymmetric shocks. Additionally, our period of analysis, 1997-2013, covers more years of the actually functioning of the Eurozone and we use quarterly data, instead of annual data.

The remainder of this paper is structured as follows. In Section 2 we analyze business cycles correlations and its determinants. Section 3 deals with the lead and lag behavior of business cycles and its determinants. In Section 4 we conclude and take some policy implications from our results.

\section{Business cycles correlations}

In this section we analyze the determinants of the cyclical nature of business cycles in the Eurozone, using data for the 18 Eurozone member countries. ${ }^{3}$ We describe in detail the variables used in this analysis, we analyze bilateral business cycle correlations, and we present the estimation methods and also the results of our estimations.

\subsection{Data treatment and analysis}

In this section we describe in detail the variables we use in this analysis. For this analysis it becomes crucial which variable to use to represent the business cycle, the variable we intend to explain. A variety of indicators have been employed in the literature. For instance, Industrial Production Index (IPI) has been used by a group of scholars to capture the economic fluctuations within EU. Some examples of these studies are Artis and Zhang (1997, 1999), Angeloni and Dedola (1999), Beine, Candelon, and Hecq (2000), Massmann and Mitchell (2004), and Camacho, Perez-Quiros, and Saiz (2006). On one hand, the main advantage of the IPI is its availability at high frequency, i.e. monthly, and its cyclical sensitivity with respect to the disturbances in macroeconomic conditions. On the other hand, its major drawback is the absence of other sectors in measurement, i.e. services, agriculture, construction, public sector, which might significantly bias the estimated business cycles. 
Another group of researchers rely on GDP data, which is a more general measure. For instance, Harding and Pagan (2001), Croux, Forni, and Reichlin (2001), Azevedo (2002), Darvas and Szapary (2004), and Altavilla (2004), have employed in their study the nominal or real GDP to measure the European business cycle. The main advantage is that it covers all sectors and, therefore, represents well the aggregate economic activity. Thus, it is likely to provide more accurate estimate of economic cycles. Given its known merits, we prefer to adopt GDP. We use quarterly GDP (in logs) at market prices from EUROSTAT, millions of national currency, chain-linked volumes, reference year 2005 (including 'euro fixed' series for euro area countries), not seasonally adjusted data, taken from EUROSTAT database. Data are for the period 1997: Q1 to 2013: Q3, for 18 Eurozone member countries, but Malta was excluded from the sample, since data for this country only begin in 2000:Q1 and we wanted to have the longest time series possible, so we were certain that we had at least one complete business cycle, so we end up with 17 Eurozone member countries. Additionally, we also use employment as another proxy for the business cycle. We use quarterly employment data for the period 1999:2-2015:4 from the EUROSTAT, defined as the number of employed workers for the age group 15-64 years. ${ }^{4}$

GDP Data was seasonally adjusted using the multiplicative ratio to moving average procedure. ${ }^{5}$ Databases from which we extracted data did not have seasonally adjusted data for most of the countries. Employment data were already seasonally adjusted.

The reason why we use quarterly data, starting from 1997 (for GDP) and 1999 (for employment) is actually twofold. First, these data-sets are available at a (high) quarterly frequency, which captures more accurately than annual data, the actual turning points of business cycles (peaks and troughs); hence the periods of booms and slumps are more correctly defined. Additionally, with this first restriction in mind, we wanted our database to include the introduction of the Euro in Eurozone economies (in 1999), since we were studying business cycles in the Eurozone, the database would have to have a common period for all countries, and also would have to include the highest number of Eurozone economies.

The business cycle measurements are classified into two groups. The first one is the classical cycles, which define business cycles movements in the level of the series (like income or employment) (Burns and Mitchell 1946). In these cycles, for an economy to experience a recession, an absolute decline in income (or employment) is necessary. In the second type of business cycles measurement, known as growth cycles, an absolute decline in the level of a series is not defined as a recession. They are defined as deviations of the economic activity from a long-term trend. Hence, these deviations/fluctuations show the growth phases, as booms (positive deviations) and slumps (negative deviations) (Hodrick and Prescott 1997; Lucas 1977). When income (or employment) is above the long-term trend, the economy goes into an upward phase. When it is below the trend, the economy enters into a downward phase. We use the growth cycles instead of the classical ones, as they represent more clearly the business cycles phases.

Regarding the methodology for business cycle extraction, there exist various filtering methods used in the literature. For instance, the Band Pass filtering developed by Baxter and King (1999) and Christiano and Fitzgerald (2003) has been extensively used. It directly extracts the cycle given a frequency interval (i.e. 18 to 96 months). Some examples of these studies are Gruben, Koo, and Millis (2002), Koopman and Azevedo (2003), Darvas and Szapary (2004), and Altavilla (2004). Some other methods are also used, to a lesser extent, such as simple output growth rates (Bordo and Helbling 2003; Kose, Prasad, and Terrones 
2003) or non-parametric Markov-Switching techniques (Altavilla 2004; Artis, Krolzig, and Toro 2004).

Among others, the Hodrick-Prescott (HP) (1997) filter that we adopt is known to be the most simple, widespread, and the most intuitive technique (adopted by Clark and van Wincoop 2001; Kose and Yi 2002; Darvas, Rose, and Szapary 2005; and Calderón, Chong, and Stein 2007). It is widely preferred, as it is more tractable than others and provides accurate estimates of business cycles. Specifically, the estimation of the cycle is based on the minimization (in $\tau$ ) of the following expression (Hodrick and Prescott 1997):

$$
\begin{gathered}
\sum_{t=1}^{T}\left(g d p_{t}-\tau_{t}\right)^{2}+\lambda \sum_{t=2}^{T-1}\left[\left(\tau_{t-1}-\tau_{t}\right)-\left(\tau_{t}-\tau_{t-1}\right)\right]^{2} \\
c y c_{t}=g d p_{t}-\tau_{t}
\end{gathered}
$$

where $g d p$ represents the actual values of the variable of interest, $\tau$ is its estimated long-term trend (potential GDP), and $\lambda$ is the penalty parameter that is used to set the smoothness of trend. The first component of (1) represents the deviations of actual GDP from its trend, while the second part represents the temporal variability of trend. So, as we attribute bigger values to $\lambda$, smoother estimates of the trend are obtained. As suggested by Hodrick and Prescott (1997), we set $\lambda=1600$ for our quarterly data. We also apply the HP-filter to the employment variable as well.

As an alternative measure of calculating the business cycle, we use the yearly first differences for GDP and employment data (which are in logarithmic values).

To have a first look at the estimated business cycles for the Eurozone countries, we depict their evolution (four graphs) in Figure 1, which shows the business cycle, calculated using GDP and employment, with both the HP-filter and first differences.

It seems that until 2008, quite idiosyncratic movements are observed with large cross-country variability in timing and amplitudes of cycles. During the financial crisis 2008-2009, countries tend to exhibit co-moving fluctuations with similar shifts in their cycle phases. This is consistent with the conventional argument and empirical findings in the literature that Eurozone economies manifest a propensity to have increasingly correlated business cycles, particularly after the introduction of the European Exchange Rate Mechanism (Fatás 1997; Montoya and de Haan 2008). However, from 2011 onwards, synchronization tends to decline again.

To investigate the synchronization further, we calculate the Pearson's bilateral correlation coefficient for the business cycle of each pair of Eurozone countries: $\rho_{i j}=\operatorname{corr}\left(c y c_{i}, c y c_{j}\right)$, where $\rho_{i j}$ represents the correlation between the cycles of country $i$ and $j$. We document the results in Table 1 from which it is worthy to note that the bilateral correlations' coefficients range between 0.017 and $0.90 .^{6}$

To be able to have a more general idea about the degree of synchronization of business cycles, we calculate average bilateral business cycles correlations and present the results in Table 2. We use both GDP and employment and also the two de-trending methods - HP and first differences. Additionally, we have another measure, in which we have calculated the business cycle, using GDP, but removing the two years of the financial crisis (2008 and 2009). Hence, we define five different business cycle variables. The first is $\rho \_G D P H P$ that denotes the average bilateral correlation coefficients calculated by using the HP-filter and 

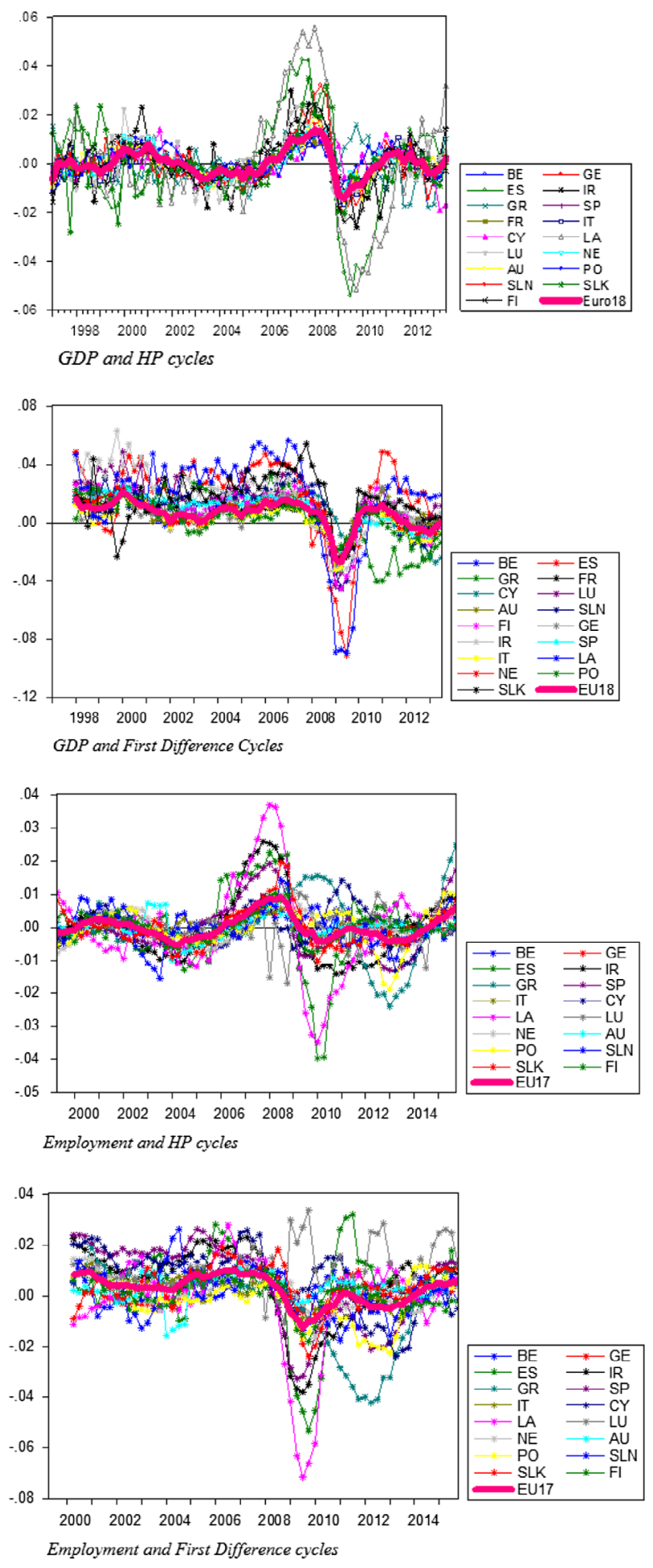

Figure 1. Business cycles in Eurozone countries.

Note: BE: Belgium, GE: Germany, ES: Estonia, IR: Ireland, GR: Greece, SP: Spain, FR: France, IT: Italy, CY: Cyprus, LA: Latvia, LU: Luxembourg, NE: Netherlands, AU: Austria, PO: Portugal, SLN: Slovenia, SLK: Slovakia. 


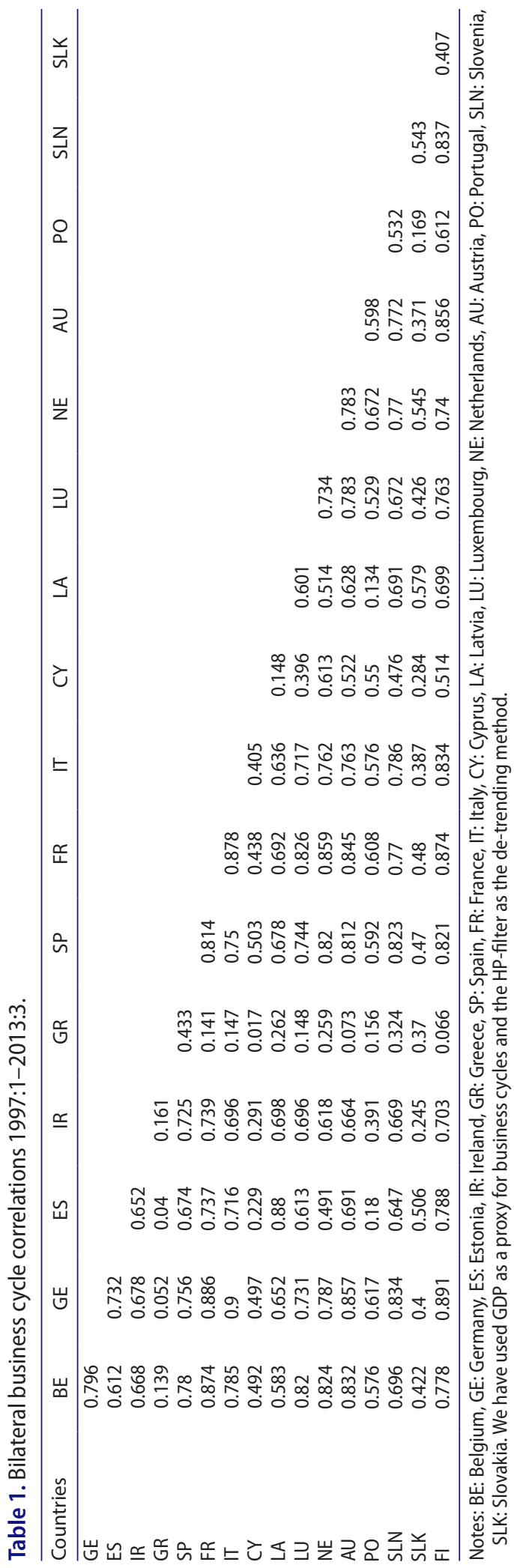


Table 2. Average bilateral business cycles correlations.

\begin{tabular}{lc}
\hline Variable type & Correlation coefficient \\
\hline$\rho_{-} G D P H P$ & 0.615 \\
$\rho_{-} G D P F D$ & 0.694 \\
$\rho \_E M P H P$ & 0.361 \\
$\rho_{-} E M P F D$ & 0.318 \\
$\rho_{-} G D P H P$ withoutcrisis & 0.538 \\
\hline
\end{tabular}

GDP data, the second is $\rho_{-} G D P F D$ that denotes average bilateral correlation coefficients calculated by using the first differences method and GDP data, the third is $\rho_{-} E M P H P$ that denotes average bilateral correlation coefficients calculated by using the HP-filter and employment data, the fourth is $\rho_{-} E M P F D$ that denotes average bilateral correlation coefficients calculated by using the first difference method and employment data, and finally $\rho \_G D P H P \_$withoutcrisis represents average bilateral correlation coefficients calculated by using the HP-filter and GDP data, but excluding the financial crisis years, 2008 and 2009. ${ }^{7}$

In general, we observe that among Eurozone member countries, average bilateral business cycles correlations are between 0.61 and 0.69 when we use GDP and between 0.32 and 0.36 when we use employment. Results are quite low, especially compared to results for the US (in Carlino and Sill (2001), the cross regional business cycle correlations in the US are often above 0.8 ). These results are a signal of heterogeneous cyclical movements between each other (de-synchronization). It is worthwhile to note that business cycles calculated using the employment variable, are far less synchronized than the GDP cycles. Another interesting observation is that when we exclude the crisis years, the average bilateral business cycle correlations fall from 0.61 to 0.53 . Hence, this supports the argument that the global financial crisis was an influential term for the synchronization of Eurozone countries' business cycles.

The analysis we made so far is static, since it refers to the entire period. To be able to observe the evolution of business cycle correlations over time, we perform a dynamic analysis based on rolling window correlations between business cycles of each country and the aggregate Eurozone business cycle. In fact, Weyerstrass et al. (2011) have introduced in their study the cyclical convergence criterion - if all Eurozone countries tend to have a perfect correlation with the aggregate Eurozone cycle, one may speak of business cycle convergence. In that case, cross-sectional means of correlations should approach 1, while the standard deviation should approach zero. To check this, we calculate the correlations for rolling windows with a 5-year time span and present the cross-sectional average and standard deviation of these correlations in Figure 2 for four different measures of the business cycle.

For business cycles using GDP, we can clearly see that mean correlations have been rising from 2002 to 2008, followed by a decline afterward, settling around [0.7-0.8], recently. Although a general trend to improve correlations is observed, it is still far from a perfect correlation, which indicates the presence of asymmetries in the cyclical shifts of member states. Accordingly, standard deviation of correlations decreased until 2008, exhibit a through during the financial crisis and then exhibit a trend to increase and hit a high level of 0.35 during the most recent period. Overall, correlations tend to decline in the last few years and exhibit a greater heterogeneity among member states.

For business cycles using employment, the evolution of correlations is somehow similar, although the level of synchronization is comparatively low. With both de-trending methods, the mean correlations tend to increase until 2009, falling sharply afterward, and increase 


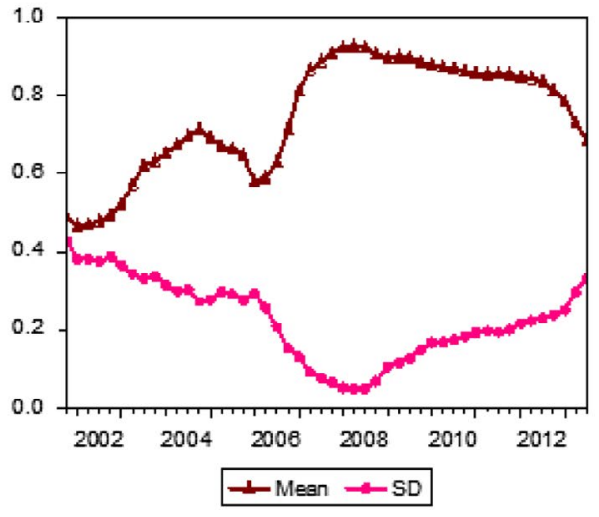

GDP and HP Cycles

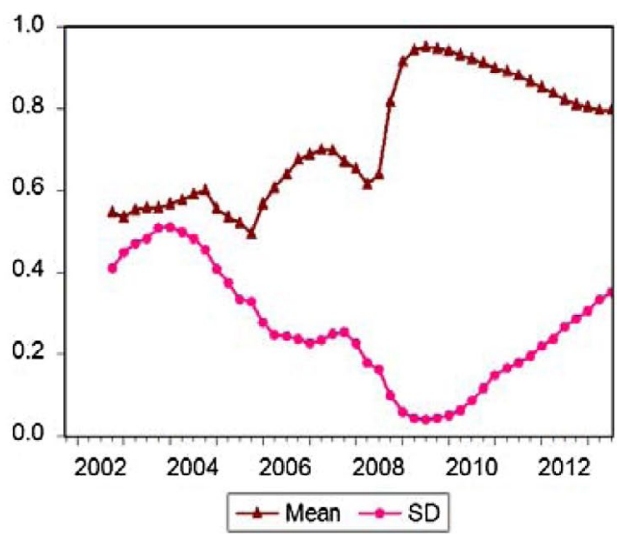

GDP and First Difference Cycles

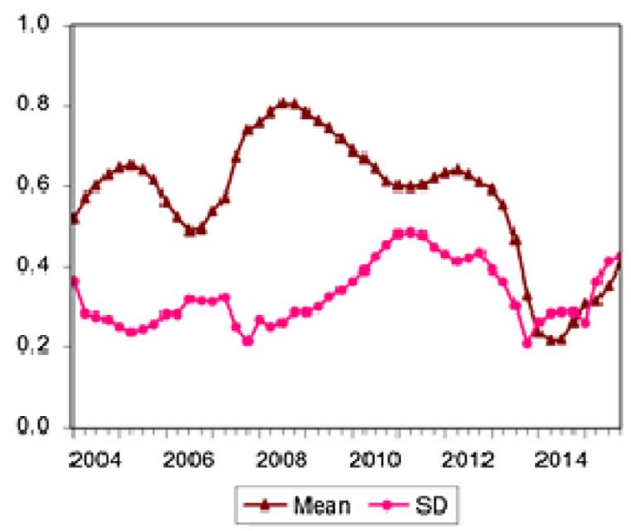

Employment and HP Cycles

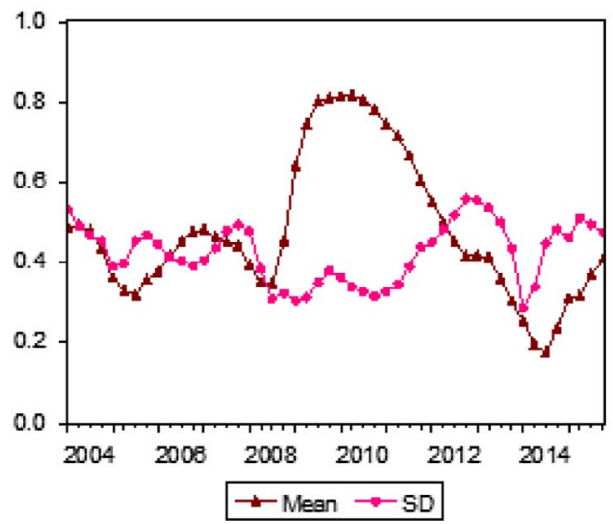

Employment and First Difference Cycles

Figure 2. Five-year rolling window correlation between countries and the aggregate Eurozone's business cycle.

Note: End points of intervals have been illustrated, i.e. 2001:4 represents the period of 1997:1-2001:4 period.

again after 2014. The cross-country dispersion of correlations continues to be persistent (and stationary), exhibiting neither a declining nor an increasing pattern.

One may consequently argue that synchronization in Eurozone had a tendency to increase until the Global crisis and to decline afterward.

To study the possible determinants of business cycles correlations, we construct a simultaneous 4-equations model, represented below, to investigate empirically the determinants of correlations/synchronization:

$$
\begin{gathered}
\rho_{i j}=\alpha_{0}+\alpha_{1} T_{i j}+\alpha_{2} L_{i j}+\alpha_{3} S_{i j}+\alpha_{4} F_{i j}+\alpha_{5} \text { Bord }_{i j}+\alpha_{4} \text { Lang }_{i j} \varepsilon_{i j} \\
T_{i j}=\gamma_{0}+\gamma_{1} S_{i j}+\gamma_{2} \text { Bord }_{i j}+\gamma_{3} \text { Lang }_{i j}+\gamma_{4} \text { GDPprod }_{i j}+\gamma_{5} \operatorname{GDPpcprod}_{i j}+\gamma_{6} \text { GDPgap }_{i j}+\delta_{i j} \\
S_{i j}=\vartheta_{0}+\vartheta_{1} T_{i j}+\vartheta_{2} F_{i j}+\vartheta_{3} \operatorname{GDPprod}_{i j}+\vartheta_{4} \operatorname{GDPpcgap}_{i j}+\mu_{i j}
\end{gathered}
$$




$$
L_{i j}=\varphi_{0}+\varphi_{1} S_{i j}+\varphi_{2} \operatorname{GDPpcgap}_{i j}+\varphi_{3} \text { GDPgap }_{i j}+\omega_{i j}
$$

In our empirical analysis, we employ a broad range of variables from different sources. The first independent variable is the bilateral trade intensity among member states $-\left(T_{i j}\right)$ - It is measured on the basis of the following formula used in Imbs (2004):

$$
T_{i, j}=\frac{X_{i, j}+M_{i, j}}{G D P_{i}+G D P_{j}}
$$

where $X_{i, j}$ and $M_{i, j}$ are the flows of exports and imports, respectively, from country $i$ to $j$ in 2005. The commodity flows are measured by trade in value-added data (which is a unit of measurement that shows the volume of exports and imports in terms of value added) provided by the OECD and the World Trade Organization for the year 2005. The expected sign of $\alpha_{1}$ is positive as commonly argued in the literature, such that intense bilateral trade between countries is likely to create input-output linkages, which will cause the increase in business cycle correlation (Baxter and Kouparitsas 2005; Frankel and Rose 1998). In other words, pairwise trade intensity is an important determinant of business cycle synchronization, which leads to a synchronization of economic shocks, spillover of economic phases, and hence, synchronizing business cycles (Lee 2010). This spillover effect is likely to be more pronounced if the trade is done within the same industry (in the form of intra-industry trade (Fidrmuc, Ikeda, and Iwatsubo 2012; Garnier 2004). ${ }^{8}$

A counter argument on trade is, however, provided by Krugman (1991) according to whom if trade openness causes a further specialization of countries in different industries (as standard Ricardian trade theory suggest), than any sector specific shock will become a country-specific shock that will create dispersed cyclical movements and asynchronous fluctuations.

The second determinant, $L_{i j}=\left|L_{i}-L_{j}\right|$, represents the dissimilarity of labor market rigidity between two countries. We measure $L$ using Employment Protection for Regular Contracts (EPRC) inside a country, using data from the OECD Indicators of Employment Protection (EPRC_V1) - Strictness of employment protection - individual and collective dismissals (regular contracts). The data are available for the period 1985-2013, for which we use the average of period values. The expected sign of $\alpha_{2}$ is negative. Countries that have similar labor market characteristics are likely to respond at similar times and with similar magnitudes to economic shocks (Fonseca, Patureau, and Sopraseuth 2010). Hence, their economic cycles are expected to be more correlated. In other words, dissimilarity in labor market institutions like employment protection laws or direct taxation rules, will contribute to the reduction of cycle correlation between two countries (Fonseca, Patureau, and Sopraseuth 2010).

Alternatively to $L_{i j}$, we use Net External Migration, which we call migr $_{i j}{ }^{9}{ }^{9}$ The reason why we use also an alternative indicator is to ensure the robustness of our estimations with respect to different labor market proxies. We take Net External Migrations from the EUROSTAT, using the net migration rate for the period 1997-2012, for each one of the 15 Eurozone member countries. We then calculate $\operatorname{Migr}_{i j}=\left|\operatorname{Migr}_{i}-\operatorname{Migr}_{j}\right|$, representing the dissimilarity of external labor mobility between two countries. The values are averaged over the period. As with $L_{i j}$ the expected sign of $\alpha_{2}$ is negative. These two labor market variables work as adjustment channels in the case of the occurrence of asymmetric shocks. 
$S_{i j}$ measures the dissimilarity in industrial structure between two countries (Imbs 2004; Krugman 1991):

$$
S_{i j}=\frac{1}{N} \sum_{t} \sum_{n=1}^{5}\left|s_{n, j, t}-s_{n, i, t}\right|
$$

where $N$ is the total number of years considered $(N=1, \ldots, t)$. In our case, the data are available from 2000 to 2009. $n$ denotes a specific industry and $s$ is a set of sectoral shares in total Gross Value Added (GVA) of that country. In terms of industries, it includes agriculture, industry, construction, public sector, services, and finance industries. We obtain these data from the EUROSTAT. The expected sign of $\alpha_{3}$ is negative: the countries which specialize in similar industries are likely to have more correlated business cycles, hence structural similarity works as a business cycle synchronization determinant. This is supported both theoretically and empirically in the literature. The main argument is that two countries with different industrial characteristics will react arbitrarily to any sector-specific shock, (Krugman 1991). On empirical grounds, Clark and van Wincoop (2001), Imbs (2004), and Magrini, Gerolimetto, and Duran (2013) report evidence in favor of the negative impact of industrial dissimilarity on the co-movement of business cycles.

$F_{i j}$ represents the financial openness in terms of FDI between countries. It is measured using the FDI data. Specifically, we use inward and outward FDI stocks (from UNCTAD) data for each country and for the period of 2002-2012 (11 years). Specifically, $F$ is defined as in Imbs (2004):

$$
\begin{gathered}
F_{i j}=\sum_{t=1}^{11} \frac{F D I_{t, i}+F D I_{t, j}}{G D P_{t, i}+G D P_{t, i}} \\
F D I_{t, i}=F D I_{\text {inward }, t, i}+F D I_{\text {outward }, t, i}
\end{gathered}
$$

where $F D I_{i, t}$ is the FDI stock of country $i$ at year $t$. Actually, FDI consists of two components - inward and outward FDI stocks. The sum of these two stocks for both countries divided by the sum of GDP for both countries helps to measure the financial openness in terms of FDI of two countries. The expected sign of $\alpha_{4}$ is positive, i.e. the higher the financial openness of countries, the higher their integration, as in Imbs (2004). ${ }^{10}$ This variable will work as a determinant of business cycles correlations.

Additionally, we have defined the common border (Bord) and common language (Lang) variables. These variables are the dummies used to measure the impact of having common borders and languages between the Eurozone countries. They take value 1 if countries have common borders and languages, respectively, and 0 otherwise. These variables are also considered to be business cycles synchronization determinants.

In Equation (3) the dependent variable is the pairwise correlation of business cycles between country $i$ and $j$ for 14 or 15 Eurozone countries $-\rho_{i j}$, depending on the variable used. When we use GDP, we had to exclude Latvia and Cyprus from our data-set due to lack of data. When we use employment, we had to exclude Latvia, Cyprus, and France due also to lack of data. Hence, we have 105 pairs of countries when we use GDP and 91 pairs for business cycles using employment. As mentioned previously, four different dependent variables 
are used in equation ( 3 ) and these are respectively: $\rho \_G D P H P, \rho \_G D P F D, \rho \_E M P H P$, and $\rho \_G D P H P \_$withoutcrisis.

In this first equation, $S, T$, and $L$ are known to be endogenous to $\rho_{i j}$ (Imbs 2004). They are assumed to affect synchronization and also to be affected by the remaining variables. This is quite plausible, as specialization, trade, and labor market disparities are known to be very interdependent to each other and to other exogenous variables. To allow for such endogeneity and define the simultaneity channels, we model the determinants of $S$, $T$, and $L$ in the remaining equations. Common language and common border are naturally exogenous, since they are cultural and geographical factors, it is plausible to accept them as given factors.

In Equation (4), bilateral trade integration of countries is, firstly, related to industrial similarity $(S)$. So, if $\gamma_{1}<0$ it means that most of international trade is done at the intraindustry level. Variables Bord and Lang are expected to naturally promote further trade integration as indicated in the literature (Imbs 2004). GDPprod, GDPgap, and GDPpcprod are the remaining exogenous variables that are supposed to affect trade integration. The first one is the multiplication of the GDPs of both countries, measuring the total (bilateral) market size. The second one is the difference in the size of two economies (disparities in market size), and the third one is the multiplication of per capita incomes (total (bilateral) development levels). Data to calculate these variables were taken from the EUROSTAT, and were converted to logarithms. The variables are available for the period 1997-2013; however, average values are adopted in the calculation. These variables actually represent the exogenous determinants which are commonly used as instruments in the literature, since the literature in this field assumes that total (bilateral) market size, disparities in market sizes, and total (bilateral) development levels are exogenously occurring factors (see Imbs (2004) for their possible effects). In terms of their possible impact, GDPprod and GDPpcprod are expected to influence positively trade integration, i.e. as two countries constitute a greater market place (captured by GDPprod) or a richer economic area (captured by GDPpcprod), they are likely to have more trade opportunities, integration, and commodity flows. We, therefore, find it crucial to include both variables.

Equation (5) includes the determinants of industrial dissimilarity among the member states. It is primarily related to trade and FDI. The expected sign for both $\vartheta_{1}$ and $\vartheta_{2}$ are positive. So, as economies integrate via trade or investments, it is expected of them to specialize in different industries. This fact is well known from the classical Ricardian trade theory. After countries develop more intense trade ties, they are likely to specialize in different industries in accordance with their relative comparative advantage (relative productivity) or according to their relative abundance in production factors (Ohlin 1933; Ricardo 1817). Similarly, increasing bilateral financial ties, particularly in the form of direct investments, will naturally make countries specialize in different industries. Hence, $\vartheta_{1}$ and $\vartheta_{2}$ are expected to be positive, as trade and financial integration will lead to dispersion in industrial specialization.

The other two determinants are GDPprod and GDPpcgap. Similar to the third equation, the two variables represent the exogenous factors which are used to instrument the industrial differences across countries. Both variables are expected to have a positive coefficient. The rationale behind this is motivated by the fact that as two member states constitute a greater market place (captured by GDPprod) and show a discrepancy in the level of development (captured by GDPpcgap), they are likely to specialize in different industries, which creates dissimilar sectoral economic structures. 
Finally, Equation (6) consists of the determinants of labor market dissimilarity of countries. The first determinant is $S$ and its expected sign is positive. So, countries with arbitrary industrial structures are likely to have dispersed labor market characteristics. The other two variables are GDPpcgap and GDPgap. Both are expected to have a positive effect. Such that the pairs of countries with large differences in its level of development (GDPpcgap) and market size are expected to have differentiated labor market characteristics. This seems plausible given the fact that more developed states (i.e. Germany, Belgium) are likely to develop distinguished welfare and labor market institutions compared to less developed ones (i.e. Greece, Cyprus), such that rate of unionization or level of unemployment benefits will be very different among these countries. For these reasons, we find it worthwhile to include both variables in the equation.

\subsection{Estimation methods and results}

We estimate our model using two methodologies. First, we use Ordinary Least Squares (OLS) and estimate the model equation-by-equation, assuming no endogeneity and simultaneity. Second, we estimate it using a 3SLSs algorithm since it allows simultaneity (as in Imbs 2004).

Table 3 presents the results from equation-by-equation OLS estimates. In this table there are eight columns, showing the results from the different regression specifications. In the first four regressions business cycles calculated using GDP are used as the dependent variable, adopting alternatively the HP-filter and the first differences methods. The fifth and sixth regressions use employment as the variable to calculate business cycles. In the last two columns, we use GDP as the measure for business cycles, but excluding the financial crisis years (2008 and 2009).

The first equation models the determinants of synchronization $(\rho)$. Regarding regressions in which GDP as a measure for business cycles is used (columns 1-4, 7, and 8) the $T$ and $L$ variables are found to have a significant effect on synchronization while others are insignificant. The sign of the trade variable is positive and indicates the fact that pair of countries which have strong trade ties and bilateral commodity flows are likely to share the economic fluctuations and exhibit more coherent cycles. This finding is quite in line with the conventional argument that intense input-output linkages among the countries cause the transfer of economic shocks and lead to more correlated shifts in their business cycles (Baxter and Kouparitsas 2005; Frankel and Rose 1998; Lee 2010). Indeed, this has largely been supported by the empirical literature. For instance, Frankel and Rose (1998) has, initially, examined the linkage between trade intensity and synchronization for 21 industrial countries and reported evidence of the positive impact of trade. Similarly, De Haan, Inklaar, and Sleijpen (2002) have found an inducing effect of trade on synchronization among 18 OECD countries between 1961 and 1997.

The second variable, $L$, which is one of our special focuses, has a negative and significant coefficient. This negative sign means that member states with large differences in labor market institutions, such as discrepancy in the level of labor market flexibility, unionization and unemployment legislation, are likely to respond arbitrarily to economic circumstances and end up with asynchronous economic cycles. In contrast, countries that exhibit similar characteristics of labor markets are likely to have more correlated cycles. This finding has been empirically supported by the literature as well. One particular work by Fonseca, Patureau, and Sopraseuth (2010) focused on the link between labor market institutions and 


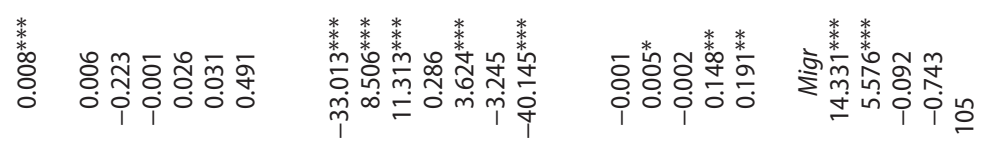

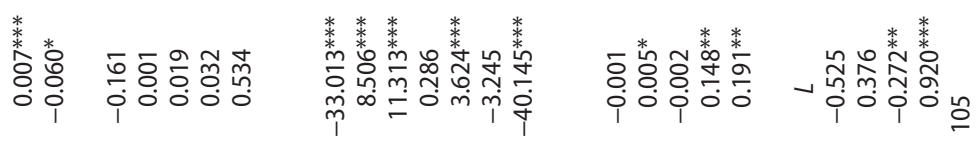

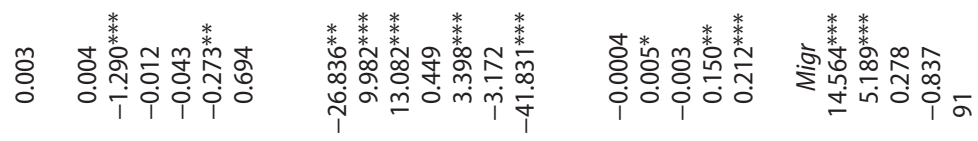

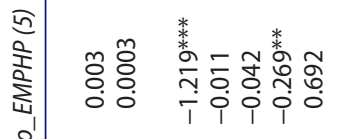

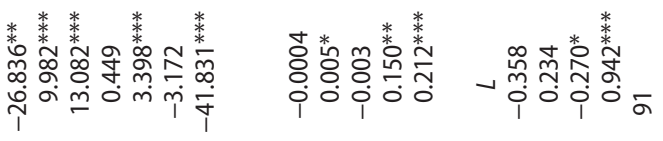

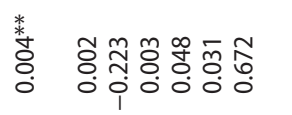

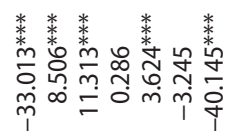

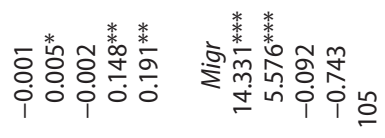

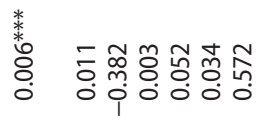

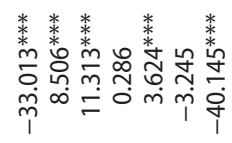

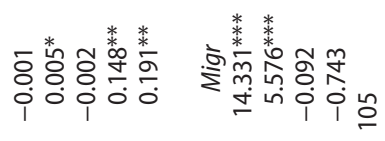
aิ

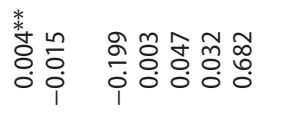

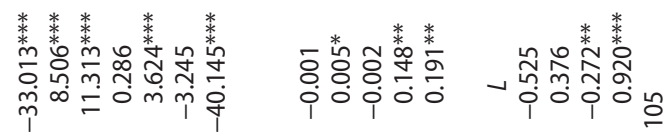
䊁类

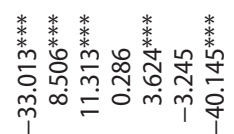

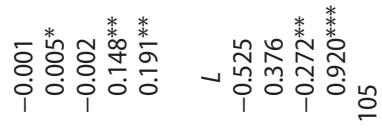

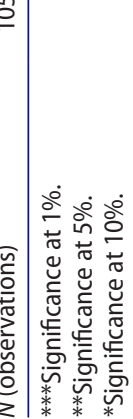


GDP co-movement among 20 OECD countries between 1964 and 2003. They find that labor market heterogeneity reduces the business cycle co-movements. Such that, discrepancy in employment protection laws and direct taxation lowers the association of business cycles, while disparities in union density, indirect taxation, and unemployment benefits enhance the synchronization. The remaining variables $S$ and $F$ have an insignificant effect in the equation.

Regarding regressions in which employment as a measure of business cycles is used (columns 5 and 6), neither trade nor the labor market dissimilarity variable are significant. However, industrial dissimilarity has a strongly significant (negative) coefficient. This is in line with the expectation that pairs of countries that exhibit large dissimilarities in industrial structures tend to be less synchronized, compared to other pairs. Other variables are insignificant, except for the language variable, which oddly presents a negative sign.

The second equation in the model includes the determinants of trade integration. All variables except GDPprod and GDPgap are significant. To begin with $S$, it has a negative and significant coefficient in all regressions indicating the fact that the majority of international trade is done at the intra-industry level. This is argued to induce business cycle synchronization to a greater extent, when compared to the impact of inter-industry trade (Fidrmuc, Ikeda, and Iwatsubo 2012; Garnier 2004). Additionally, we find that having common borders and languages contributes to trade integration among the pairs of countries as it lowers transport costs. It also enhances the minimization of information costs since it is easier to develop commercial networks and relationships among trading partners. GDPpcprod has a significant (positive) coefficient, i.e. pairs of countries that constitute a rich and developed economic zone are likely to have more intense trade ties.

The third equation consists of the determinants behind industrial dissimilarity. Financial integration and GDPpcgap variables have a positive and significant coefficient, consistently in all columns. So, the two countries with intense financial ties are likely to specialize in different industries in accordance with their comparative advantage. Similarly, countries with large difference in the level of welfare and development are likely to have an arbitrary industrial structure.

Finally, regarding the last equation, the determinants of $L$ or migr are modeled. For the $L$ variable (modeled in columns 1, 2, 5, and 7) only GDPgap is significant. It has a negative coefficient, indicating the fact that pair of countries which have large differences in market size, are likely to have similar labor market characteristics, perhaps signaling similar labor market legislation. As for the determinants of migr, only the GDPpcgap and the $S$ variables have a significant (positive) coefficient. This can be understood as pairs of countries that have large disparity in development and industrial structure between them, are likely to have large disparity also in net migration pattern.

Although the results we have so far obtained are satisfactory and consistent with the theory, equation-by-equation estimates should be interpreted cautiously for two reasons. First, it is not designed to capture the possible endogeneity in the relationships between variables, which might, in turn, bias significantly the results. Second, it does not allow the simultaneity and, thus, we are not able to observe the direct and indirect impacts of variables on each other (Imbs 2004; Magrini, Gerolimetto, and Duran 2013). To address these issues, we estimate the system using a 3SLS estimator introduced by Zellner and Theil (1962). In 3SLS estimations, a three step procedure is followed. Initially, endogenous and exogenous variables are defined in each equation. For instance, all variables in the first equation are 
endogenous (except F, Lang, and Bord, as indicated in the literature Imbs (2004). S is an endogenous variable in the second equation, $T$ in the third, and $S$ in the last equation. In the first step of estimation, endogenous variables are regressed on exogenous variables (instruments), except the ones that are in the same equation with endogenous variables. In the second step, a consistent covariance matrix for equation disturbances is estimated. In the third step, the fitted values from first step regressions are used to estimate the coefficients and their standard errors. Results are presented in Table $4 .{ }^{11}$

In the first equation, we observe the direct impact of variables on business cycle correlations. In the regressions in which we use GDP as the business cycles measure, the $T$ and $L$ variables have a significant coefficient, with the same sign as in Table 3, with the OLS estimation. Hence, the legitimacy of these variables has been shown once more. Migration has a significant coefficient only in one column. Lang has a significant (negative) sign in columns (1), (2), and (7) and $S$ has a significant (positive) sign in columns (3), (4), and (8), which goes against the theory. In the regressions for which employment is used as the business cycles measure, again $S$ has a significant (negative) coefficient.

In the second and third equation, the sign of the coefficients are almost all consistent with the OLS estimations, with approximately the same level of significance. In the last equation, the determinants of $L$ and migr are all consistent with the OLS estimation, with the same signs and similar level of significance.

Overall, one may speak of two main results from the three stages least squares estimations. First, trade integration and labor market similarity are the main driving forces behind synchronization patterns. The implications are quite similar to the previous findings. The migration variable has a negative and significant coefficient in the first equation, which means that heterogeneous labor market characteristics lead to a decline in the association of business cycles. All other estimated determinants are consistent with the previous estimations.

Overall, in this section, we have seen that traditional determinants of business cycle synchronization (measure with GDP), such as trade, are found to have the expected signs for coefficients. More interestingly, a less emphasized factor by the literature; labor market dissimilarity, is found to be robustly evident and, therefore, critical to business cycle correlations, either if we use labor market protection statistics or net external migration. ${ }^{12}$

However, these dynamics are true only for business cycles measured with GDP. The dynamics of business cycles calculated using the employment variable, are somewhat different. The major driving force behind business cycles synchronization in this case is the dissimilarity in industrial specialization of countries.

\section{Lead and lag behavior of business cycles}

While the previous section focused on the determinants of the contemporaneous correlation of business cycles of the Eurozone member countries, in this section we are going to assess if the determinants of the leads and lags of business cycles are different from the ones found in the previous section. If differences exist, they are particularly important to be known for policy-makers, especially if asymmetric shocks exist between Eurozone member countries. 


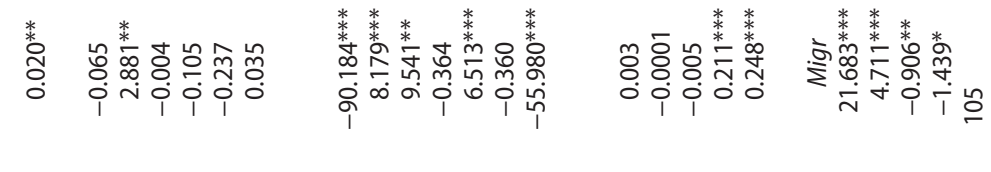

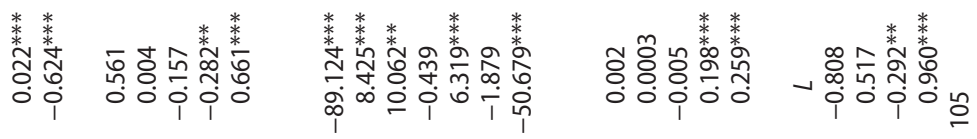

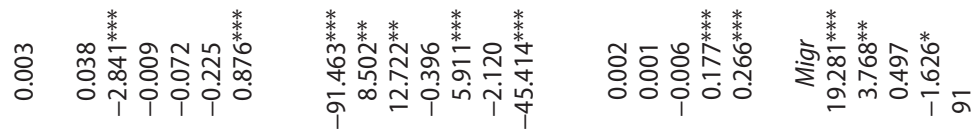

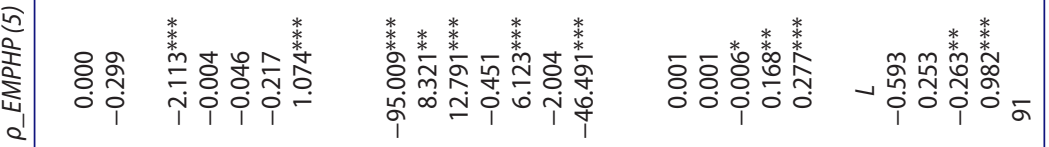

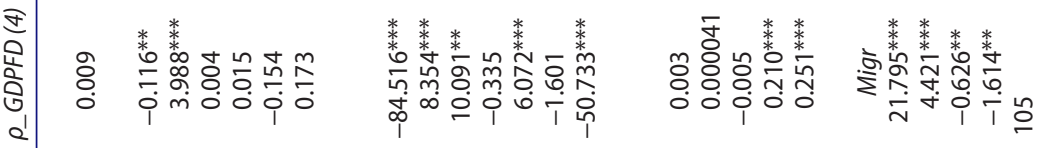

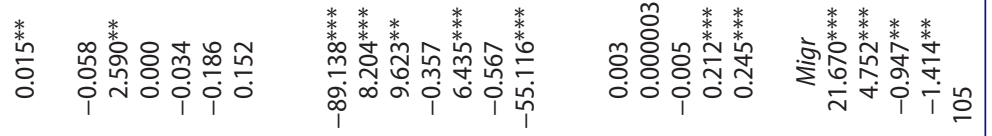

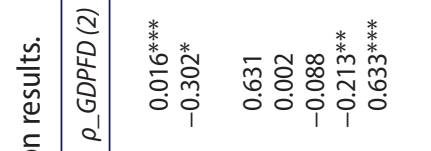

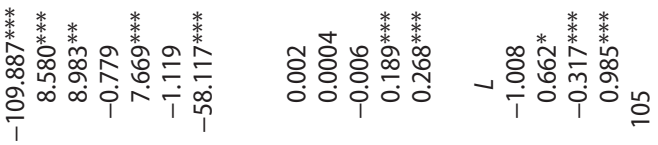

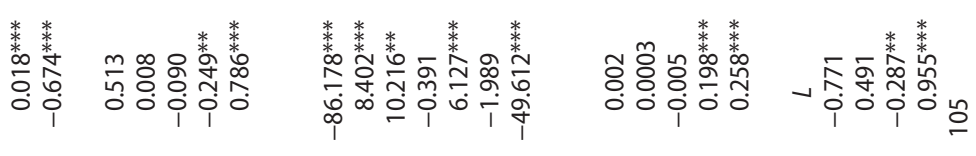




\subsection{Methodology}

The second aim of the present study is to understand the lead/lag behavior across business cycles of the Eurozone member countries. To be able to investigate this, we first need to identify the turning points (i.e. peaks and troughs) within the business cycles of each country and the aggregate Eurozone cycle. To do so, we employ the HP-filter de-trended GDP series and apply a Bry-Boschan (1971) algorithm to estimate the turning points.

In terms of methodology for turning point detection, several tools have been developed in the literature (see Harding and Pagan 2002a). To provide a brief account, early literature has focused on the replication of official turning points in the US declared by National Bureau of Economic Research. For instance, Bry and Boschan (1971) have introduced the initial algorithm for this purpose. The detected turning points were found to overlap well with the official ones. Harding and Pagan (2002b) have generalized this algorithm and designed it for quarterly data. Despite its accuracy and simplicity, it has been criticized for several reasons. The major argument emphasizes the fact that the results obtained are likely to depend on the subjective choice of several parameters (i.e. maximum phase length parameter, etc.).

Alternatively, following Hamilton's (1989) pioneer work, Owyang, Piger, and Wall (2005) have employed a Markov-Switching model to identify the timing of the shifts in the US business cycle. This model allows the growth rate to switch across different growth regimes (like low growth and high growth regimes). Specifically, it calculates the probabilities of different business cycle phases, which are used then to identify the timing of turning points. Although, it represents a more general approach, i.e. being more consistent with data generating process, it has been criticized for being less intuitive.

Given its simplicity and accuracy, we prefer adopting the Bry-Boschan (1971) program in our study. The algorithm follows a two-step procedure. In the first step, it calculates a set of local minima and maxima in the series then imposes several restrictions to ensure a certain level of phase duration. In terms of parameters used, the local maxima/minima have been searched in every 2 quarters; thus, the window length is 2 quarters, which is the default value. The minimum length of a phase (expansion or recession) is 2 quarters and minimum cycle length is 5 quarters. (For a detailed description of the algorithm see Duran (2014) or the BUSY program manual user guide).

Having detected the turning points, the next empirical issue is to construct a model to investigate the possible determinants of lead/lag behavior across member states. In fact, there is a scant empirical literature on this subject. The majority of the work done in this field does not use the information from turning points in the determination of lead/lag patterns, but refers mostly to the dynamic correlation analyses among the business cycles. This makes our study more interesting per se.

One example of such studies is implemented by Kang (2011), who analyzed the lead/lag patterns in an international context. He obtained a (quarterly) data-set that covers EU15 members, US, Australia, Canada, and Japan over the period 1985-2009. He employed various variables including output, employment, TFP, and investment. He concludes that the US business cycle tends to lead the business cycle of other countries. The lead/lag pattern is more pronounced in employment cycles compared to other variables. In terms of determinants, he considered labor market differences, disparity in GDP and population across countries. Most interestingly, he reports evidence in favor of the fact that the countries that 
have a more rigid labor market tend to lag more the US cycle. Hence, labor market flexibility is shown to be critical in lead/lag behavior.

In the case of the US, several studies exist. Sill (1997) has, for instance, identified the leading and lagging regions using quarterly employment data for eight Bureau of Economic Analysis (BEA) regions and for the period 1955-1995. Moreover, he argues that most of the leading regions have large employment share in manufacturing and a lesser share in services and government. Similarly, Magrini, Gerolimetto, and Duran (2013) have investigated the determinants of lead/lag behavior across 48 states between 1979 and 2010 and found that states that specialize in high-tech goods tend to anticipate persistently the business cycles. Lastly, Park and Hewings (2003) have studied the cyclical behavior of five Midwest states and found that states that specialize more in manufacturing tend to respond more promptly to economic shocks.

The analysis we propose here attempts to follow a comprehensive approach and include industrial, income, and labor market variables. The empirical model takes the following form:

$$
\begin{aligned}
L L_{i j}= & \partial_{0}+\partial_{1} \text { income_pc }_{i j}+\partial_{2} \text { industry }_{i j}+\partial_{3} \text { construction }+\partial_{4} E P R C_{i j} \\
& +\partial_{5} \text { migration }_{i j}+\partial_{6} \text { finance }_{i j}+\partial_{7} F D I_{i j}+\emptyset_{i, j}
\end{aligned}
$$

The dependent variable $L L_{i, j}=L L_{i}-L L_{j}$, represents the lead of country i's business cycle over country $j$ 's (in quarters). By lead(lag) we refer to the dynamic correlations of business cycles, in our case, countries which are leading the Eurozone business cycle (others that lag behind the Eurozone business cycle). We are not analyzing causality.

Since there are 15 countries in our data-set, the number of observations is $105 . L L_{i}$ is the mean (or median) lead/lag of country i's turning points with respect to the Eurozone cycles' over the period of analysis (1997-2013). $L L_{j}$ is the mean (or median) lead/lag of country j's turning points with respect to the Eurozone cycles'. (+) sign denotes the lead and (-) denotes the lag behavior.

In terms of the independent variables; income $\backslash p c_{i j}=i n c o m e \backslash p c_{i}-i n c o m e \backslash p c_{j}$ represents the difference in per capita incomes between country $i$ and $j ;$ ind $u s t r y_{i j}$, construction $_{i j}$, and finance $_{i j}$ represent the variables that capture the differences in industrial specialization. For instance, construction $_{i j}=$ construction $_{i}-$ construction $_{j}$ captures the discrepancy between country $i$ and js GVA share of construction sector in the total GVA of that country. In terms of the labor market variable $E P R C_{i j}=L_{i}-L_{j}$, represents the disparity in labor market rigidity between $i$ and $j$, while migration $_{i j}=$ migr $_{i}-$ migr $_{j}$ represents the bilateral differences in net external migration. For all variables, averaged values over the corresponding periods are used. Finally, $F D I_{i j}=F D I_{i}-F D I_{j}$ represents the differences in the share of FDI stock (sum of 2002-0212 period) relative to GDP between $i$ and $j$.

\subsection{Results}

The estimated turning points are displayed in Table 5. For the aggregate Eurozone cycle, four peaks and four troughs are found. For each member state, the durations of lead and lags are presented (in quarters). An empty cell in the table means that the country does not experience any turning point around the national turning point. In the last three columns, mean, median, and modes of leads/lags are summarized for each country.

In terms of mean values, the maximum lead is 1.14 quarters (Netherlands) and the maximum lag is 1.625 quarters (Slovakia). 


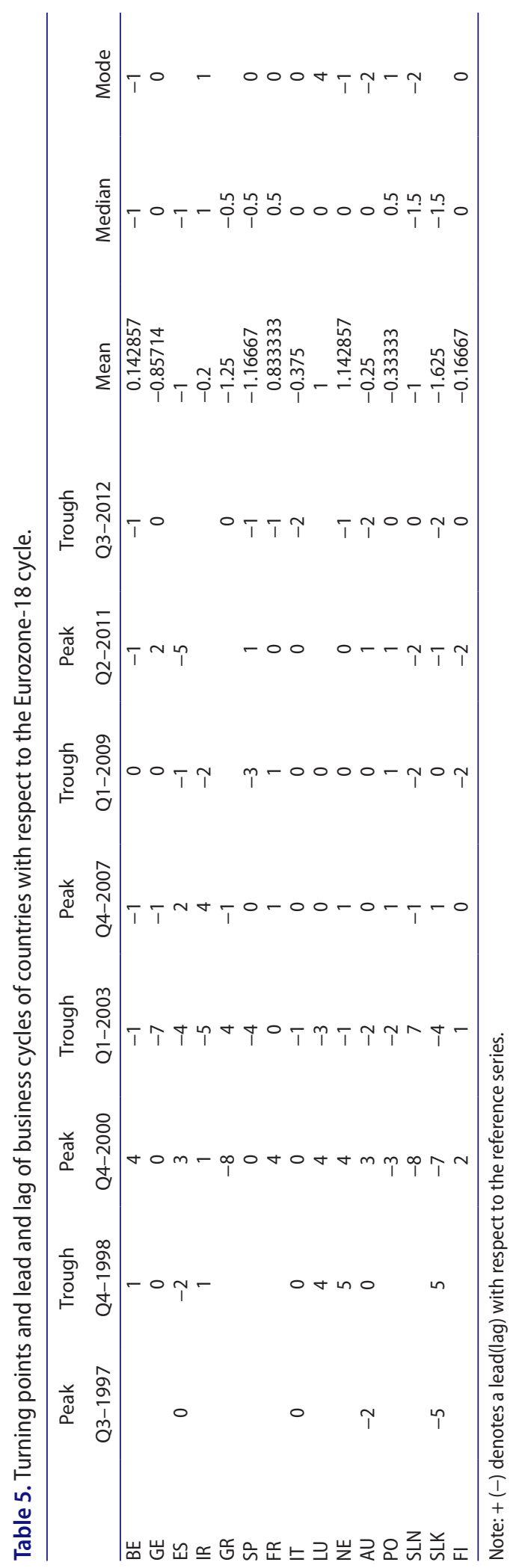




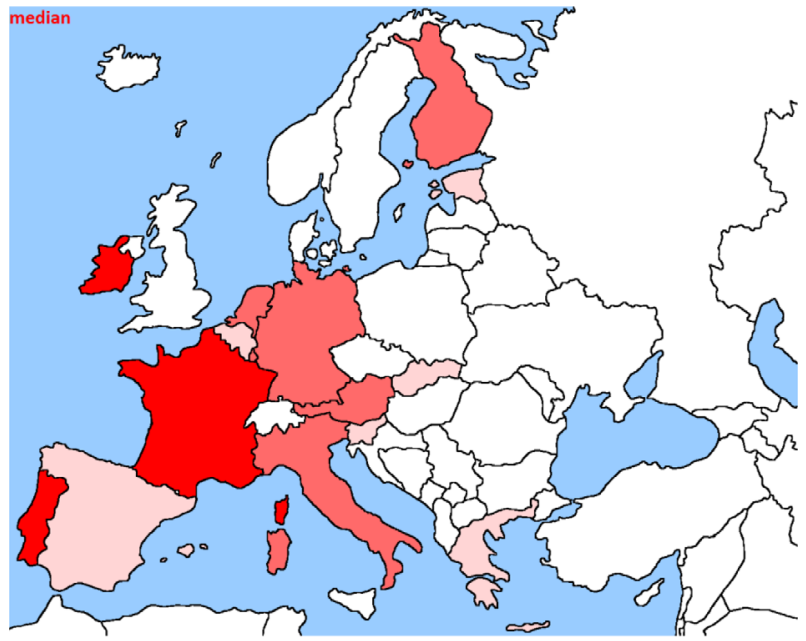

(a). Median

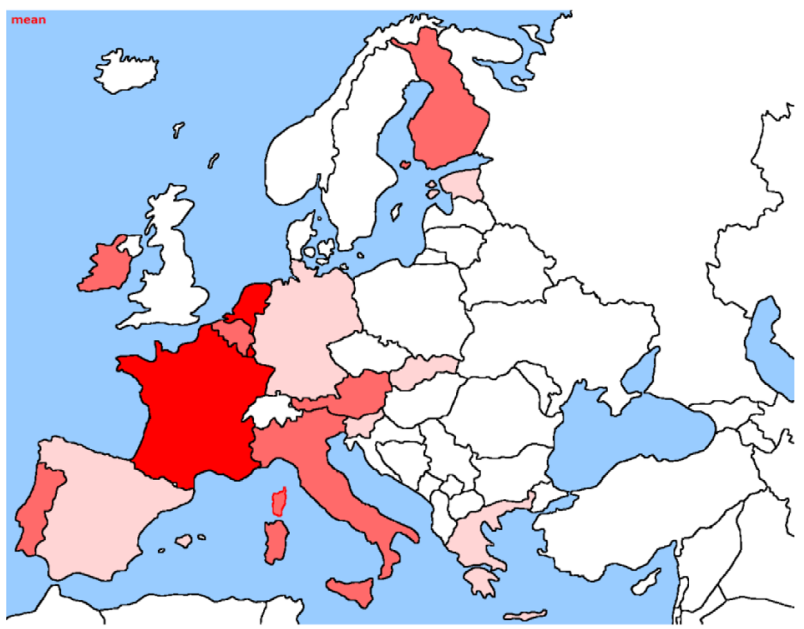

(b). Mean

\begin{tabular}{|c|c|}
\hline$>0.5$ & leading \\
\hline$(-0.5,0.5)$ & coincident \\
\hline$<-0.5$ & lagging \\
\hline
\end{tabular}

Figure 3. Distribution of lead and lag behavior of countries.

To provide a more general picture, we present in the following maps (Figure 3) the geographical distribution of leads/lags within Eurozone. The dark red color represents the countries which are at least 0.5 quarters a head of the aggregate Eurozone cycle while the lightest pink color represents the lagging states.

Although no clear geographical pattern is observed at a glance, some interpretations can be made on the type of leading countries. Firstly, Western countries seem to exhibit a leading behavior over the Eastern ones. Second, particularly some states like Luxembourg, France, and the Netherlands seem to anticipate the business cycles. In terms of lagging countries, 
Table 6. Determinants of lead and lag behavior.

\begin{tabular}{lcccc}
\hline & Model (1) & Model (2) & Model (3) & Model (4) \\
Dependent variable: $L L$ & Mean & Median & Mean & Median \\
\hline Independent variables & & & & \\
Constant & -0.174608 & $0.209673^{* *}$ & $-0.137019^{*}$ & $0.150815^{*}$ \\
income_pc & $3.576004^{* * *}$ & $4.982975^{* * *}$ & $3.846269^{* * *}$ & $4.723701^{* * *}$ \\
Industry & $-6.277529^{* * *}$ & -1.009176 & $-4.010959^{* *}$ & $-2.756781^{* *}$ \\
Construction & 3.467382 & $33.62886^{* * *}$ & $12.60721^{* * *}$ & $27.29532^{* * *}$ \\
EPRC & -0.015047 & $0.490683^{* * *}$ & $0.249172^{* * *}$ & $0.385897^{* * *}$ \\
Migration & $-0.159569^{* * *}$ & $-0.258637^{* * *}$ & $-0.222785^{* * *}$ & $-0.193724^{* * *}$ \\
Finance & 2.480721 & $3.77386^{* * *}$ & - & - \\
FDI & - & - & $0.071815^{* * *}$ & -0.010226 \\
& & & 105 & 105 \\
$N$ & 105 & 105 & 0.85 & 0.72 \\
R-squared & 0.75 & 0.75 & & 1.52 \\
Diagnostics & & & $1.79^{*}$ & $23.90^{* * *}$ \\
White-Heterosc. & 1.43 & 1.09 & $61.76^{* * *}$ & 1.40 \\
Breusch-Pagan & $66.55^{* * *}$ & $37.43^{* * *}$ & 0.95 & 26.299 \\
Jarque-Bera & 0.81 & 0.74 & 1.39 & \\
AlC & 1.93 & 1.64 & & \\
\hline
\end{tabular}

Note: HAC (heteroscedasticity-autocorrelation consistent estimators used), White-Heterosc represents White's heteroscedasticity test $(F)$ statistics, Breusch-Pagan denotes LM serial correlation test statistics, and Jarque-Bera is the normality of errors test.

*** Significance at $1 \%$.

**Significance at $5 \%$.

*Significance at $10 \%$.

some Eastern and South Eastern European economies like Greece, Slovakia, and Slovenia tend to display a lagging behavior.

To be able to provide a more systemic analysis, we summarize below in Table 6 the regression results obtained from the estimation of Equation (7). There are four different versions of regression results. In the first and third columns, the dependent variable $(L L)$ has been calculated using mean values of lead/lag indicators and in the second and fourth columns median values have been used instead. Finance and FDI variables have not been included in the same regression to avoid a possible multi-collinearity problem. Hence, in the first two models the Finance variable has been used, while FDI has been employed in the last two models.

The findings provide several intuitive results. First, income_pc has a positive and significant coefficient (at 1\%) in all regressions, which means that more developed (richer) countries tend to lead the business cycles of relatively low income countries. This finding underlines the relevance of demand shocks.

Second, construction has a positive and significant coefficient in almost all regressions. This finding is consistent with the literature, i.e. the construction sector is known to be particularly sensitive to economic cycles. It has also been perceived as a credit-dependent investment good, making its demand more sensitive to changes in the interest rate. Hence, as it is a cyclically responsive sector, countries that have a larger share of the construction sector tend to respond earlier to economic disturbances.

In contrast with our expectations, we are not able to observe the same effect for the industry variable, as its impact is negative and significant. This might have occurred due to the presence of both durable and non-durable goods production in industry. 
The two variables regarding the labor market characteristics (EPRC and migration) have a strongly significant coefficient in almost all regressions. Hence, one may argue that labor market differences play a critical role in lead/lag of business cycles. EPRC has a positive coefficient, while the migration variable has a negative sign. However, both signs are in contrast with the conventional view that economies which have flexible labor market and with mild employment protection, can adjust the real wages easily and move more quickly toward new equilibrium level of employment (Kang 2011). Hence, it is likely that the employment levels of such economies respond to shocks promptly. However, we observe that the countries in which employees are more protected and the labor force is less mobile, quicker shifts in employment have been observed. This result is as surprising as it is interesting, which needs a clearer explanation in our future research.

Finally, finance and FDI variables are also found to be partially important. They both have a positive and significant coefficient in the second and third regressions. This actually means that as a country is more open to international financial movements (in terms of direct investment), it naturally becomes more exposed to global shocks. Hence, economic developments in other countries can inevitably spillover to the country. Moreover, this effect is even more pronounced within the countries that have a higher share of employment in the finance sector, captured by the finance variable.

Overall, having implemented our analysis, typical economies that may lead the business cycles in the Eurozone can be defined in a following way: relatively wealthier states with high level of income, welfare regimes with strict employment legislation, the ones which specialize more in construction and finance sectors, and more open to international capital movements are likely to anticipate the business cycles in the Eurozone.

\section{Conclusions and policy implications}

In this work we study the determinants of business cycle correlation and of the lead and lag behavior of business cycles in the Eurozone, i.e. business cycles synchronization of Eurozone member countries. We analyze if the determinants usually identified in the literature bilateral trade intensity, dissimilarity in industrial structures, financial openness, and FDI relations - are relevant also for the Eurozone and estimate by means of OLS and 3SLS techniques. Additionally, we also use new measures of labor market dissimilarity - dissimilarity of labor market rigidity, net external migration - to study business cycle synchronization.

Bilateral trade intensity and the dissimilarity of labor market rigidity are important factors of business cycles correlations in the Eurozone, although this is found to be evident only for business cycles proxied by GDP. Results are robust to the use of the HP-filter and first-differences as the de-trending method, and also to the use of GDP excluding the financial crisis years (2008 and 2009). The dynamics of synchronization in the context of business cycles proxied by an employment variable are somewhat different and driven by industrial dissimilarity.

As for the determinants of bilateral trade intensity we uncover that trade is done mostly at the intra-industry level and countries which constitute a rich economic zone have more intense trade ties in the Eurozone. Industrial dissimilarity reacts to a positive gap in financial openness and to higher differences in welfare/development and also in the economic structure. Labor dissimilarity in what concerns labor protection is smaller when bilateral market size of countries are very different, and when labor dissimilarity is measured by net 
external migration we observe that countries that have large disparities in development and economic structures are likely to have large differences also on net migration patterns.

In what concerns the lead behavior of business cycles, the most important factors to determine its behavior are income per capita, countries with stricter employment legislation, countries which present a higher specialization in the construction and finance sectors, and countries more open to international capital movements. The behavior of the labor market variables are in sharp contrast to what is expected in the literature and it is an avenue for future research.

Taking into account our results, policy-makers in the Eurozone should take careful attention to countries which do not share the level of intra-industry trade that some Eurozone member countries do, since this characteristic of international trade seems to be important for business cycles' synchronization. Additionally, stronger trade ties, independently of the type of trade, are important for business cycles synchronization; hence further product market integration measures should be analyzed. The harmonization of labor market protection legislation should be taken in consideration also, since the possibility of asymmetrical shocks can be enhanced if large asymmetries are present. Additionally, economic policies should be aimed at dissipating different levels of economic development between countries, since these differences lead to business cycles' lack of synchronization.

Differences in the determinants between contemporaneous business cycles and lead and lag behavior of business cycles are especially important for policy-makers in the Eurozone also to know about, in particular if asymmetric shocks between countries are set in place.

\section{Notes}

1. The UK held a referendum in June 2016 and a majority of citizens voted to leave the EU, but for now, since negotiations haven't started, we are still considering this country as a fullmember of the EU.

2. In Section 2, in which we present a discussion on the variables used, we will present some examples of the results achieved by the literature for other countries. In the Introduction we will focus on the Eurozone, which is our region of analysis.

3. Eurozone Member Countries (in parenthesis is the date of Eurozone accession): Austria (1999), Belgium (1999), Cyprus (2008), Estonia (2011), Finland (1999), France (1999), Germany (1999), Greece (2001), Ireland (1999), Italy (1999), Latvia (2014), Luxembourg (1999), Malta (2008), Netherlands (1999), Portugal (1999), Slovakia (2009), Slovenia (2007), and Spain (1999).

4. Employment data is used for 17 Eurozone countries, excluding France, since the series was not available for this country.

5. The empirical analyses in this paper has been implemented using EVIEWS 6, STATA 9.1, and BUSY software packages.

6. In Table 1, business cycles are calculated using GDP, with the HP-filter.

7. In the estimations below, we do not present results for the variable $\rho_{-} E M P F D$ due to space considerations. Results are available upon request.

8. Inklaar, Jong-A-Pin, and de Haan (2008) found a positive, yet small, effect of trade on business cycle synchronization. Factors like specialization and monetary and fiscal policy convergence have a similar impact.

9. When we use $m i g r_{i j}$ in the estimations, we don't use $L_{i j}$ in the estimations.

10. Contrary to most of the literature Cerqueira and Martins (2009) found a negative (and significant) relationship between financial openness and business cycle synchronization.

11. Alternative to 3SLS, there are various methods available in the literature, such as instrumental variables or GMM approaches. However, these methods require a number of well defined 
'instruments' which we lack considerably. For this reason, we estimate our system of equations with a 3 SLS approach.

12. We also tried to estimate the impact of other known determinants such as similarity of fiscal and monetary policy among the member states but never found a significant effect.

\section{Acknowledgments}

The authors would like to thank two anonymous referees for helpful comments. Alexandra FerreiraLopes would also like to thank the Portuguese National Science Foundation (FCT).

\section{Disclosure statement}

No potential conflict of interest was reported by the authors.

\section{Funding}

This work was supported by the Fundação para a Ciência e Tecnologia [grant number UID/ GES/00315/2013].

\section{References}

Altavilla, C. 2004. "Do EMU Members Share the Same Business Cycle?" JCMS: Journal of Common Market Studies 42 (5): 869-896.

Anagnostou, A., I. Panteladis, and M. Tsiapa. 2015. "Disentangling Different Patterns of Business Cycle Synchronicity in the EU Regions." Empirica 42: 615-641.

Angeloni, I., and L. Dedola. 1999. "From the ERM to the Euro: New Evidence on Economic and Policy Convergence among EU Countries." ECB Working Paper No. 4, Frankfurt.

Antonakakis, N., and G. Tondl. 2014. "Does Integration and Economic Policy Coordination Promote Business Cycle Synchronization in the EU?” Empirica 41 (3): 541-575.

Arestis, P., and P. Phelps. 2016. "Endogeneity Analysis of Output Synchronization in the Current and Prospective EMU.” JCMS: Journal of Common Market Studies 54 (3): 525-543.

Artis, M., H. M. Krolzig, and J. Toro. 2004. "The European Business Cycle." Oxford Economic Papers 56 (1): 1-44.

Artis, M. J., and W. Zhang. 1997. "International Business Cycles and the ERM: Is There a European Business Cycle?" International Journal of Finance and Economics 2 (1): 1-16.

Artis, M. J., and W. Zhang. 1999. "Further Evidence on the International Business Cycle and the ERM: Is There a European Business Cycle?" Oxford Economic Papers 51: 120-132.

Asteriou, D., and A. Moudatsou. 2015. "Business Cycle Synchronization in the Enlarged EU: The Role of Bilateral Trade and FDI." Review of Development Economics 19 (1): 196-207.

Azevedo, J. V. 2002. "Business Cycles: Cyclical Comovement within the European Union in the Period 1960-1999: A Frequency Domain Approach.” Banco De Portugal Working Paper No. 5-02, Lisbon.

Baxter, M., and R. G. King. 1999. "Measuring Business Cycles: Approximate Band-pass Filters for Economic Time Series." Review of Economics and Statistics 81 (4): 575-593.

Baxter, M., and M. A. Kouparitsas. 2005. "Determinants of Business Cycle Comovement: A Robust Analysis." Journal of Monetary Economics 52 (1): 113-157.

Beine, M., B. Candelon, and A. Hecq. 2000. "Assessing a Perfect European Optimum Currency Area: A Common Cycles Approach.” Empirica 27: 115-132.

Bordo, M. D., and T. Helbling. 2003. "Have National Business Cycles Become More Synchronized?" NBER Working Paper No. 10130, Cambridge.

Böwer, U., and C. Guillemineau. 2006. "Determinants of Business Cycle Synchronization across Euro Area Countries.” ECB Working Paper No. 587, February, Frankfurt. 
Bry, G., and C. Boschan. 1971, "Cyclical Analysis of Time Series: Selected Procedures and Computer Programs.” NBER Technical Paper, No 20, Cambridge.

Burns, A. F., and W. C. Mitchell. 1946. Measuring Business Cycles. New York: NBER.

Calderón, C., A. Chong, and E. Stein. 2007. "Trade Intensity and Business Cycle Synchronization: Are Developing Countries Any Different?” Journal of International Economics 71: 2-21.

Camacho, M., G. Perez-Quiros, and L. Saiz. 2006. "Are European Business Cycles Close Enough to Be Just One?" Journal of Economic Dynamics and Control 30: 1687-1706.

Caporale, G. M., R. De Santis, and A. Girardi. 2015. “Trade Intensity and Output Synchronisation: On the Endogeneity Properties of EMU." Journal of Financial Stability 16: 154-163.

Carlino, G., and K. Sill. 2001. "Regional Income Fluctuations: Common Trends and Common Cycles." Review of Economics and Statistics 83 (3): 446-456.

Cerqueira, P. A., and R. Martins. 2009. "Measuring the Determinants of Business Cycle Synchronization Using a Panel Approach." Economics Letters 102: 106-108.

Christiano, L., and T. J. Fitzgerald. 2003. “The Band-pass Filter." International Economic Review 44 (2): 435-465.

Clark, T. E., and E. van Wincoop. 2001. "Borders and Business Cycles." Journal of International Economics 55: 59-85.

Croux, C., M. Forni, and L. Reichlin. 2001. "A Measure of Comovement for Economic Variables: Theory and Empirics." Review of Economics and Statistics 83: 232-241.

Darvas, Z., A. K. Rose, and G. Szapary. 2005. "Fiscal Divergence and Business Cycle Synchronization: Irresponsibility is Idiosyncratic." NBER Working Paper No. 11580, Cambridge.

Darvas, Z., and G. Szapary. 2004. "Business Cycle Synchronization in the Enlarged EU: Comovements in the New and Old Members." Central Bank of Hungary Working Paper No. 2004/1, Budapest.

de Haan, J., R. Inklaar, and R. Jong-A-Pin. 2008. "Will Business Cycles in the Euro Area Converge? A Critical Survey of Empirical Research.” Journal of Economic Surveys 22 (2): 234-273.

De Haan, J., R. Inklaar, and O. Sleijpen. 2002. "Have Business Cycles Become More Synchronized?" JCMS: Journal of Common Market Studies 40 (1): 23-42.

Duran, H. E. 2014. "Short-run Dynamics of Income Disparities and Regional Cycle Synchronization in the U.S." Growth and Change 45 (2): 292-332.

Fatás, A. 1997. "EMU: Countries or Regions? Lessons from the EMS Experience." European Economic Review 41 (3-5): 743-751.

Fidrmuc, J., and I. Korhonen. 2006. "Meta-analysis of the Business Cycle Correlation between the Euro Area and the CEECs." Journal of Comparative Economics 34: 518-537.

Fidrmuc, J., T. Ikeda, and K. Iwatsubo. 2012. "International Transmission of Business Cycles: Evidence from Dynamics Correlations." Economics Letters 114: 252-255.

Fonseca, R., L. Patureau, and T. Sopraseuth. 2010. "Business Cycle Comovement and Labor Market Institutions: An Empirical Investigation.” Review of International Economics 18 (5): 865-881.

Frankel, J. A., and A. K. Rose. 1998. “The Endogenity of the Optimum Currency Area Criteria." The Economic Journal 108 (449): 1009-1025.

Furceri, D., and G. Karras. 2008. "Business-cycle Synchronization in the EMU." Applied Economics 40 (12): 1491-1501.

Garnier, J. 2004. “To What Extent Does Intra-industry Trade Matter in Business Cycles Comovements? Distinguishing Common and Transmitted Cycles." Mimeo, Economics Department, European University Institute, Florence.

Gouveia, S., and L. Correia. 2013. "Trade Integration and Business Cycle Synchronization in the Euro Area: The Case of Southern European Countries.” Journal of Economic Integration 28 (1): 85-107.

Gruben, W. C., J. Koo, and E. Millis. 2002. "How Much Does International Trade Affect Business Cycle Synchronization?” Federal Reserve Bank of Dallas Working Paper No. 0203, Dallas.

Hamilton, J. D. 1989. "A New Approach to the Economic Analysis of Nonstationary Time Series and the Business Cycle." Econometrica 57 (2): 357-384.

Harding, D., and A. R. Pagan. 2001. "Extracting, Analysing and Using Cyclical Information." MPRA Paper No. 15.

Harding, D., and A. R. Pagan. 2002a. "A Comparison of Two Business Cycle Dating Methods." Journal of Economic Dynamics and Control 27: 1681-1690. 
Harding, D., and A. R. Pagan. 2002b. “Dissecting the Cycle: A Methodological Investigation.” Journal of Monetary Economics 49: 365-381.

Hauge, J. P. and P.-S. V. Skulevold. 2011. "Fiscal Policy Convergence and Business Cycle Synchronization in the Euro Area." Master thesis, BI Norwegian Business School, Master of Science in Political Economy.

Hodrick, R. J., and E. C. Prescott. 1997. "Postwar U.S. Business Cycles: An Empirical Investigation.” Journal of Money, Credit, and Banking 29: 1-16.

Imbs, J. 2004. “Trade, Finance, Specialization, and Synchronization." Review of Economics and Statistics 86 (3): 723-734.

Inklaar, R., R. Jong-A-Pin, and J. de Haan. 2008. "Trade and Business Cycle Synchronization in OECD Countries - A Re-examination.” European Economic Review 52: 646-666.

Kang, M. 2011. "Leading and Lagging Relationships in International Business Cycles." Mimeo, Fudan University.

Kappler, M. 2011. "Business Cycle Co-movement and Trade Intensity in the Euro Area: Is There a Dynamic Link?” Journal of Economics and Statistics 231 (2): 247-265.

Koopman, S. J. and J. V. Azevedo. 2003. "Measuring Synchronization and Convergence of Business Cycles." Tinbergen Institute Discussion Paper No. 2003-052/4, Amsterdam.

Kose, M. A., E. A. Prasad, and M. E. Terrones. 2003. "How Does Globalization Affect the Synchronization of Business Cycles?" American Economic Review 93: 57-62.

Kose, M. A., and K. Yi. 2002. "The Trade Comovement Problem in International Macroeconomics." Federal Reserve Bank of New York Staff Report No. 155, New York.

Krugman, P. R. 1991. Geography and Trade. Cambridge, MA: MIT Press.

Lee, Jim 2010. "Trade Integration and Business Cycle Comovement: Evidence from the U.S." The International Trade Journal 24 (4): 361-388.

Lucas, Robert E. 1977. "Understanding Business Cycles." Carnegie-Rochester Conference Series on Public Policy 5 (1): 7-29.

Magrini, S., M. Gerolimetto, and H. E. Duran. 2013. "Business Cycle Dynamics across the US States." The B.E Journal of Macroeconomics 13 (1): 795-822.

Massmann, M., and J. Mitchell. 2004. "Reconsidering the Evidence: Are Eurozone Business Cycles Converging?" Journal of Business Cycle Measurement and Analysis 1 (3): 275-308.

Montoya, L., and J. de Haan. 2008. "Regional Business Cycle Synchronization in Europe?" International Economics and Economic Policy 5 (1-2): 123-137.

Ohlin, B. 1933. Interregional and International Trade. Cambridge, MA: Harvard University Press.

Owyang, M. T., J. Piger, and H. J. Wall. 2005. “Business Cycle Phases in U.S. States." Review of Economics and Statistics 87: 604-616.

Park, Y., and G. J. D. Hewings. 2003. "Does Industry Mix Matter in Regional Business Cycles?" Regional Economics Applications Laboratory Discussion Paper No. 29, Illinois.

Pentecôte, J.-S., J.-C. Poutineau, and F. Rondeau. 2015. "Trade Integration and Business Cycle Synchronization in the EMU: The Negative Effect of New Trade Flows." Open Economies Review 26: 61-79.

Ricardo, D. 1817. On the Principles of Political Economy and Taxation. Ontario: Batoche Books Kitchener.

Siedschlag, I., and G. Tondl. 2011. "Regional Output Growth Synchronisation with the Euro Area." Empirica 38: 203-221.

Sill, K. 1997. "Regional Employment Dynamics." Federal Reserve Bank of Philadelphia Working Paper No. 28, Philadelphia.

Solomos, D., T. Papageorgiou, and D. Koumparoulis. 2013. "Financial Sector and Business Cycles Determinants in the EMU Context: An Empirical Approach (1996-2011)." European Research Studies Journal 16 (2): 34-58.

Weyerstrass, K., B. van Aarle, M. Kappler, and A. Seymen. 2011. "Business Cycle Synchronisation With(in) the Euro Area: In Search of a 'Euro Effect." Open Economies Review 22 (3): 427-446.

Zellner, A., and H. Theil. 1962. "Three-stage Least Squares: Simultaneous Estimation of Simultaneous Equations.” Econometrica 30: 54-78. 